\title{
Evaluation Index System of Marine Ecological Environment
}

\author{
Congcong Xing ${ }^{1,2,3}$, Jing $\mathrm{Li}^{1,2}$, Xiuren $\mathrm{Li}^{4}$, and Bei Zhao ${ }^{1,2^{*}}$ \\ ${ }^{1}$ North China Sea Environmental Monitoring Center, State Oceanic Administration, Ministry of Natural Resources, Qingdao 266033, \\ China \\ ${ }^{2}$ Shandong Provincial Key Laboratory of Marine Ecology and Environment \& Disaster Prevention and Mitigation, Qingdao 266061, \\ China \\ ${ }^{3}$ Hainan Key Laboratory of Marine Geological Resources and Environment, Hainan Marine Geological Survey Academy, 570206, \\ Haikou, China \\ ${ }^{4}$ College of Oceanic and Atmospheric, Ocean University of China, Qingdao 266100, China
}

\begin{abstract}
Based on the model of ecological environment evolution in the process of the economic development, this paper constructed the evaluation index system of marine ecological environment .The results were shown as follows: the evaluation index system of marine ecological environment consists of 1 object layer, 3 element layers (state of marine ecological environment pressure of marine ecological environment and response of marine ecological environment), and 15 factor layers. Index weight was calculated through combination weighting approach of subjective and objective evaluation method of analytic hierarchy process(AHP) and entropy method .The evaluation indicator system and evaluation method have general applicability and strong operability.
\end{abstract}

\section{Introduction}

With the rapid development of marine economy, the marine ecological environment is also confronted with great pressures and challenge [1-8]. Grossman et al. [9], Kenneth et al. [10] discussed the relationship between environment and economic growth then put forward the theory of Environmental Kuznets Curve (EKC); Martinez et al. [11], Kildow et al. [12] put forward the ecological environment restoration measurements of different coastal areas to promote the marine ecosystem assessment and conduct comprehensive, coordinated and sustainable development. Quicoy et al. [13] discussed ecological environment carrying capacity of the coastal tourist industry. Song et al. [14] explained the stability of marine ecological environment under the optimal control of switching forward system; Wang et al. [15] analysed the coordination in marine economic development and marine ecological environment of Guangdong province by using coupling coordination degree mode; Di et al. [16] verified the stress relationship of marine ecological environment, economy and society in the coastal areas of China; Chen et al. [17] discussed the interaction and the evolution tendency between marine economic growth and marine environmental stress.

Based on the previous research work and the model of ecological environment evolution in the process of the economic development, this paper constructed the evaluation system of ecological environment to promote the scientific estimation of the marine ecological environment in China. It can provide reference for the protection of marine ecological environment and the optimal allocation of marine resources in China.

\section{Coordinated development model}

Marine economic development and ecosystem conservation are opposite as well as united. Based on the previous research work, the relationship between marine economy and ecological environment was shown as follows (Fig.1).

As the development degree metric, $\mathrm{y}=\frac{1}{2}-x^{3}, \mathrm{y}=$ $\frac{3}{4}-x^{3}$ and $y=1-x^{3}$ denote the maximum economy development level under pressure of support for ecological environment protection and economic development. As the coordination degree metric, $\mathrm{y}=x$, $\mathrm{y}=x^{3}, \mathrm{y}=x^{\frac{1}{3}}$ divides the coordination degree into four parts: strong pressure of economic development, moderate pressure of economic development, moderate support for ecological and environmental protection, strong support for ecological and environmental protection. Arrow 1 is the trend of economic development degree; arrow 2 is the trend of coordination degree.

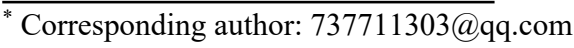




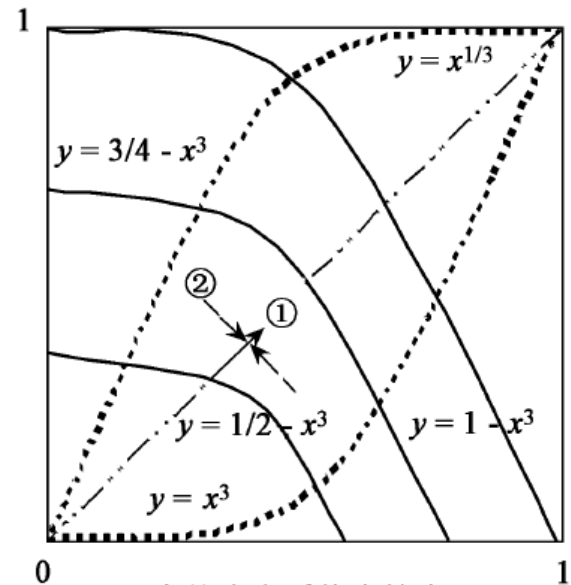

Fig.1 Marine economy and ecological environment coordinated development model

\section{Evaluation index system}

Based on the previous research work, this paper constructed the evaluation index system of ecological environment through combination weighting approach of subjective and objective evaluation method of analytic hierarchy process (AHP) and entropy method following the principles of systematicness, comprehensiveness and maneuverability. The evaluation index system of marine ecological environment consists of one object layer, three element layers(state of marine ecological environment, pressure of marine ecological environment, response of marine ecological environment) and fifteen factor layers (Table 1).

Table 1 Evaluation Index System of Marine Eecological Environment

\begin{tabular}{|c|c|c|}
\hline Object layer & Element layers & Factor layers \\
\hline \multirow{15}{*}{$\begin{array}{c}\text { Marine } \\
\text { Eecological } \\
\text { Environment } \\
\text { developmental } \\
\text { level }\end{array}$} & \multirow{5}{*}{$\begin{array}{l}\text { state of } \\
\text { marine } \\
\text { ecological } \\
\text { environment } \\
\quad\left(F_{1}\right)\end{array}$} & marine biological diversity $\left(I_{1}\right)$ \\
\hline & & per capita saltpan area $\left(I_{2}\right)$ \\
\hline & & per capita coastal wetland area $\left(I_{3}\right)$ \\
\hline & & marine natural reserves area $\operatorname{ratio}\left(I_{4}\right)$ \\
\hline & & per capita marine sand exploitation quantity $\left(I_{5}\right)$ \\
\hline & \multirow{5}{*}{$\begin{array}{l}\text { pressure of } \\
\text { marine } \\
\text { ecological } \\
\text { environment } \\
\quad\left(F_{2}\right)\end{array}$} & polluted oceanic area ratio $\left(I_{6}\right)$ \\
\hline & & erosion coast $\operatorname{ratio}\left(I_{7}\right)$ \\
\hline & & industrial solid wastes emissions per unit of land $\operatorname{area}\left(I_{8}\right)$ \\
\hline & & industrial wastewater emissions per unit of land area $\left(I_{9}\right)$ \\
\hline & & $\begin{array}{l}\text { direct economic losses from marine disasters per unit } \\
\text { coastline }\left(I_{10}\right)\end{array}$ \\
\hline & \multirow{5}{*}{$\begin{array}{l}\text { response of } \\
\text { marine } \\
\text { ecological } \\
\text { environment } \\
\quad\left(F_{3}\right)\end{array}$} & per capita gross ocean product $\left(I_{11}\right)$ \\
\hline & & marine employed person ratio $\left(I_{12}\right)$ \\
\hline & & marine scientific research personnel ratio $\left(I_{13}\right)$ \\
\hline & & per capita marine environmental protection input $\left(I_{14}\right)$ \\
\hline & & per capita marine infrastructure possession $\left(I_{15}\right)$ \\
\hline
\end{tabular}

State of marine ecological environment, which expressed the quantity and quality of marine ecological resources, consists of five factors: marine biological diversity $\left(\mathrm{I}_{1}\right)$, per capita saltpan area $\left(\mathrm{I}_{2}\right)$, per capita coastal wetland area $\left(\mathrm{I}_{3}\right)$, marine natural reserves area ratio $\left(\mathrm{I}_{4}\right)$ per capita marine sand exploitation quantity $\left(\mathrm{I}_{5}\right)$. The pressure of marine ecological environment, which expressed the pressure of human activities on marine resources and environment consists of five factors: polluted oceanic area ratio $\left(\mathrm{I}_{6}\right)$, erosion coast ratio $\left(\mathrm{I}_{7}\right)$, industrial solid wastes emissions per unit of land area $\left(\mathrm{I}_{8}\right)$, industrial wastewater emissions per unit of land area $\left(\mathrm{I}_{9}\right)$, direct economic losses from marine disasters per unit coastline $\left(\mathrm{I}_{10}\right)$. The response of marine ecological 
environment, which expressed the support of human activities to marine ecological environment protection, consists of five factors: per capita gross ocean product $\left(\mathrm{I}_{11}\right)$, marine employed person ratio $\left(\mathrm{I}_{12}\right)$, marine scientific research personnel ratio $\left(\mathrm{I}_{13}\right)$, per capita marine environmental protection input $\left(\mathrm{I}_{14}\right)$, per capita marine infrastructure possession $\left(\mathrm{I}_{15}\right)$.

\section{Evaluation index system}

The evaluation methodologies in this paper consist of three steps: standard processing of evaluation index, weight definition of evaluation index and marine ecological environment development index calculation.

\subsection{Standard processing}

Fifteen evaluation indexes of the evaluation system have different dimensions. And numerical values of positive indexes and negative indexes have different meanings. So this paper standardized the evaluation indexes using range method. The calculation formula is as follows:

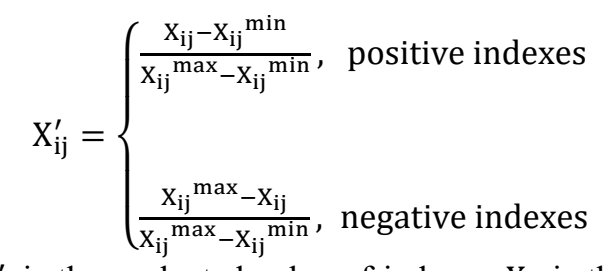

$\mathrm{X}_{\mathrm{ij}}^{\prime}$ is the evaluated value of indexes, $\mathrm{X}_{\mathrm{ij}}$ is the actual value of indexes; $X_{i j}$ max is the maximum value of indexes and $\mathrm{X}_{\mathrm{ij}}{ }^{\mathrm{min}}$ is the minimum value of indexes.

\subsection{Weight definition}

The common evaluation methodologies include objective weighting method and subjective weighting method. In this paper, index weight was calculated through combination weighting approach of subjective and objective evaluation method of analytic hierarchy process (AHP) and entropy method. The comprehensive weight can be used to evaluate the development level of marine ecological environment and provide a basis for evaluation of the marine ecological environment development level.

\subsubsection{Analytic hierarchy process (AHP)}

Analytic hierarchy process (AHP) consists of four steps: hierarchy establishment, expert evaluation, consistency test and weight definition. The calculation formula is as follows:

$$
\begin{aligned}
& \mathrm{A}_{\omega}=\gamma_{\max } \omega \\
& \mathrm{CI}=\frac{\gamma_{\max }-\mathrm{n}}{\mathrm{n}-1} \\
& \mathrm{CR}=\frac{\mathrm{CI}}{\mathrm{RI}} \\
& \omega_{\mathrm{i}}=\sum_{\mathrm{j}=1}^{\mathrm{m}} \mathrm{a}_{\mathrm{j}} \mathrm{b}_{\mathrm{ij}}
\end{aligned}
$$

$A$ is judgment matrix; $\gamma_{\max }$ is the maximum eigenvalue; $\omega$ is eigenvector; $\mathrm{CI}$ is consistency index; $\mathrm{RI}$ is random consistency index; $\mathrm{CR}$ is consistency ratio; $\mathrm{n}$ is matrix dimension; $\omega_{i}$ is combination weight; $m$ is the number of criterion layer index; $a_{j}$ is the weight of criterion layer $j$ to object layer; $b_{i j}$ is the weight of index i to criterion $\mathrm{j}$.

\subsubsection{Entropy method}

Entropy method consists of four steps: determining the index weight, calculating the index entropy value, calculating the coefficient of variation, calculating the weight. The calculation formula is as follows:

$$
\begin{aligned}
\rho_{i j} & =\frac{a_{i j}}{\sum_{j=1}^{n} a_{i j}} \\
e_{j} & =-k \sum_{i=1}^{m} \rho_{i j} \ln \rho_{i j} \\
g_{j} & =1-e_{j} \\
\varphi_{j} & =\frac{g_{j}}{\sum_{j=1}^{n} g_{j}}
\end{aligned}
$$

$\rho_{\mathrm{ij}}$ is the weight of index $\mathrm{i}$; $\mathrm{e}_{\mathrm{j}}$ is the entropy, $\mathrm{k}=$ $\ln m, i=1,2,3, \ldots, m ; \mathrm{j}=1,2,3, \ldots, n$, suppose when $\rho_{i j}=0, \rho_{i j} \ln \rho_{i j}=0 ; g_{j}$ is the coefficient of variation; $\varphi_{j}$ is the weight.

\subsubsection{Comprehensive weight definition}

We can get comprehensive weight through combination weighting approach of subjective and objective evaluation method of analytic hierarchy process (AHP) and entropy method. The calculation formula is as follows:

$$
W_{i}=\eta \omega_{i}+\left(1-\eta \varphi_{i}\right)
$$

$\omega_{i}$ is the weight of index calculated by analytic hierarchy process (AHP), $\varphi_{j}$ is the weight of index calculated by entropy method, $W_{i}$ is the comprehensive weight of index, $\eta$ is adjustment parameter, $\eta=0.5$ in this paper.

\subsection{Index calculation}

The evaluation system of ecological environment model was constructed as follows:

$$
\mathrm{T}=\sum_{\mathrm{j}=1}^{\mathrm{n}} \mathrm{P}\left(\mathrm{F}_{\mathrm{ij}}\right) \mathrm{I}_{\mathrm{j}}
$$

$\mathrm{T}$ is the index of the marine ecological environment development level; $\mathrm{P}\left(\mathrm{F}_{\mathrm{ij}}\right)$ is the combination weight value of the element layer; $I_{j}$ is the evaluation value of indexes.

\section{Conclusions}

The evaluation indicator system and evaluation method constructed in this paper have general applicability and 
strong operability, which can be widely applied to marine ecological environment development level evaluation of specific ecosystem (island, coastal zone and so on). It can also be widely applied to marine ecological environment development level evaluation of one coastal region or different coastal regions. The results we got from the evaluation indicator system and evaluation method constructed in this paper can provide a basis for evaluation of the marine ecological environment development level, so that decisions can be made to improve the efficiency of marine resource utilizing and protect the marine ecological environment.

\section{Acknowledgements:}

This study was sponsored by the North Sea Bureau, Ministry of Natural Resources (Grant No. 202102), the Shandong Provincial Key Laboratory of Marine Ecology and Environment \& Disaster Prevention and Mitigation (Grant No. 201801), and the Hainan Key Laboratory of Marine Geological Resources and Environment (Grant No. HNHYDZZYHJKF008) .

\section{References}

1. Zhu Chaoqi. 2019. Introduction to the Themed Issue on New Advances in Marine Environmental Engineering in China. Journal of Marine Environmental Engineering, 10(3): 163-164.

2. Duarte C M. 2014. Global change and the future ocean: a grand challenge for marine sciences. Frontiers in Marine Science, 1: 63.

3. Jones P J S. 2013. A governance analysis of the Galápagos Marine Reserve. Marine Policy, 41: 6571.

4. Yuanbin Fu, Yue Qi, Jing Kang, Ji Yu, Gongbo Ma, Chuanjun Wang and Yongguang Sunn. 2019. Coastal Wetland Vulnerability under the Influence of Human Activities: A Case Study of the Liaohe Estuary. Journal of Marine Environmental Engineering, 10(3): 181-193.

5. Ji-Yu C, Shen-Liang C. 2002. Estuarine and coastal challenges in China. Chinese Journal of Oceanology and Limnology, 20(2): 174-181.

6. Chuanjun Wang, Yingchao Wu, Ke Cao, Guangquan Chen, Wenquan Liu, Yuguang Wang and Yueyin Cai. (2019). Seawater Intrusion in the Coastal Area of Liaodong Bay. Journal of Marine Environmental Engineering, 10(3): 211-223.

7. Nguyen Thi The Nguyen and Grettel Gretchen. 2018. Regional Risk Zonation of Environmental Pollution on Marine and Coastal Zone]. Journal of Marine Environmental Engineering, 10(2): 97-107

8. Du Xing, Sun Yongfu, Song Yupeng, Zhu Chaoqi. 2021. In-Situ Observation of Wave-Induced Pore Water Pressure in Seabed Silt in the Yellow River Estuary of China. Journal of Marine Environmental Engineering, 10(4): 243-255.
9. Grossman G M, Krueger A B. 1994. Economic Growth and the Environment. Quarterly Journal of Economics, 110(2): 353-377.

10. Kenneth Arrow, Bert Bolin, Robert Costanza, Partha Dasgupta, Carl Folke, C.s. Holling, Bengt-owe Jansson, Simon Levin, Karl-gÖran MÄler, Charles Perrings And David Pimentel. 1996. Economic growth, carrying capacity, and the environment. Environment and Development Economics, 1(1), 104-110.

11. Martínez M L, Intralawan A, Vázquez G, PérezMaqueo O, Sutton P, and Landgrave R. 2007. The coasts of our world: Ecological, economic and social importance. Ecological economics, 63(2-3), 254-272.

12. Kildow J T, Mcilgorm A. 2010. The importance of estimating the contribution of the oceans to national economies. Marine Policy, 34(3): 367-374.

13. Quicoy A R, Briones N D. 2009. Beach carrying capacity assessment of coastal ecotourism in Calatagan, Batangas, Phlippines. Journal of Environmental Science \& Management, 12(2): 1126.

14. Song Liang, Lian Dongyan. The stability of marine ecological environment under the optimal control of switching forward system. Arabian Journal of Geosciences, 14(7): 1-6.

15. Wang Xianli, Jiang Guoqiang, Wang Junli. 2015. Evaluation of coordinated development of marine envirnment- eonomy system based on multivariate statistical methods. Marine Environmental Science, 34(5): 777-791.

16. Di Qianbin. Guo Yali. 2016. The stres rdlationship verifiation systeminteraction and coordination of the sustaina ble development of marineeconomy measure. Marine environmental science, 35(3): 453459.

17. Chen Qi, Li Jingmei. 2015. Analysis on the decoupling relationship between marine environmental stress and marine economic growth in China. Marine environmental science, 34(6): $827-$ 833. 